The authors reported no conflicts of interest.

The Journal policy requires editors and reviewers to disclose conflicts of interest and to decline handling or reviewing manuscripts for which they may have a conflict of interest. The editors and reviewers of this article have no conflicts of interest.



\section{THE NO-TOUCH \\ SAPHENOUS VEIN \\ SHOULD \\ BE CONSIDERED IN A \\ RISK SCORE OF VEIN \\ GRAFT FAILURE \\ To the Editor:}

We read with great interest the excellent article from Antonopoulos and colleagues. ${ }^{1}$ In the article, factors associated with early saphenous vein graft (SVG) failure after coronary artery bypass grafting (CABG) were explored. The authors utilized a novel approach in exploring factors of early SVG failure, a meta-analysis of individual patient data. Initially, a systematic literature search for studies reporting on SVG occlusion up to 1 year after CABG was conducted. Aggregate individual patient data were used to create a predictive model and a risk score for early SVG failure: the SAFINOUS score. Although the systematic literature search yielded 48 studies, accounting for 23,103 patients, the model and the risk score were finally based on data sharing from 5 centers, accounting for 1864 patients. We would like to propose some additional comments that might be important to consider when implementing the proposed risk score into clinical practice and potentially help in planning the operation.

Myriad factors are associated with early SVG failure after CABG. Various intraoperative technical aspects of surgery, such as the method of harvesting and the anastomotic technique, and intrinsic morphological and functional features of bypass conduits all play crucial roles in determining early SVG failure. Similarly, characteristics of the target coronaries are important determinants of short- and longterm graft performance. Furthermore, clinical risk factors linked to atherosclerosis are variably associated with graft failure as well. Many of the known factors associated

\footnotetext{
The Editor welcomes submissions for possible publication in the Letters to the Editor section that consist of commentary on an article published in the Journal or other relevant issues. Authors should: $\bullet$ Include no more than 500 words of text, three authors, and five references. • Type with double-spacing. • See http://jtcs.ctsnetjournals.org/ misc/ifora.shtml for detailed submission instructions. • Submit the letter electronically via jtcvs.editorialmanager.com. Letters commenting on an article published in the JTCVS will be considered if they are received within 6 weeks of the time the article was published. Authors of the article being commented on will be given an opportunity of offer a timely response ( 2 weeks) to the letter. Authors of letters will be notified that the letter has been received. Unpublished letters cannot be returned.
}

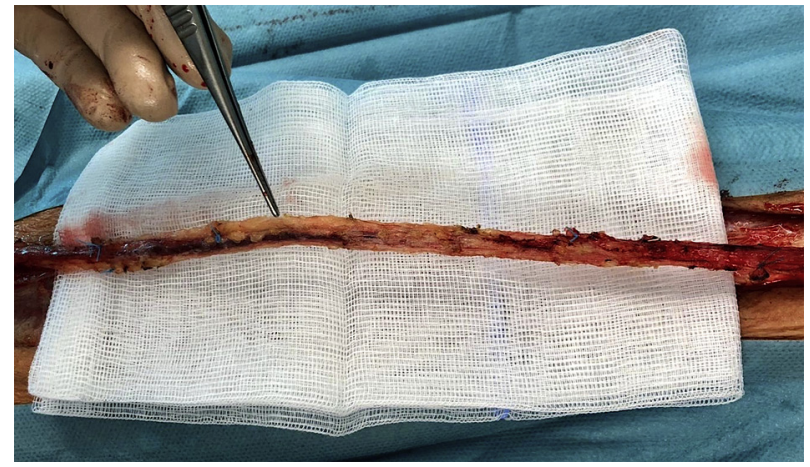

FIGURE 1. Intraoperative image during no-touch saphenous vein graft harvesting for coronary artery bypass grafting. The no-touch saphenous vein graft is harvested with a pedicle of surrounding perivascular fat tissue. This allows for minimal instrumentation during vein graft handling and avoids trauma potentially inflicted to the graft with surgical instruments. The graft is left in situ until used for bypass and manual distention is avoided. For easier orientation and to avoid twisting of the bypass graft, 1 side of the vein is consistently marked with blue dye.

with early SVG failure were reconfirmed in the analysis by Antonopoulos and colleagues. ${ }^{1}$ The logistic regression model identified predictors that were used to construct the SAFINOUS score. ${ }^{1}$ Although previously associated with increased risk of SVG failure, ${ }^{2}$ endoscopic vein harvesting was associated with a reduced risk in the SAFINOUS score of the present study. There are only a few short- and midterm follow-up studies comparing endoscopic to open vein harvesting and it appears that the patency of endoscopic vein grafts is, at best, comparable to those prepared by open vein harvesting. ${ }^{3}$ Studies looking into graft quality and histology of endoscopic vein grafts hold the explanation for these results. Endoscopic vein harvesting is suggested to be minimally invasive in terms of wound healing and scarring, although instrumentation during harvesting induces damage to vessel integrity. ${ }^{4}$ Yet, the correlation of vascular damage during endoscopic vein harvesting with clinical outcome is a matter of debate. ${ }^{4}$

Intraoperative SVG handling is a crucial factor associated with the performance of conduits for bypass. When using the atraumatic no-touch SVG harvesting technique, the saphenous vein is harvested with a pedicle of surrounding tissue to minimize vascular trauma and thus preserve the vein's normal architecture (Figure 1). No-touch SVGs have superior short-term and long-term patency over conventional venous grafts. ${ }^{5}$ During the past 25 years of notouch saphenous vein harvesting for CABG, the technique has been shown to be a rare surgical improvement that significantly enhances SVG performance, even comparable to that of the left internal thoracic artery. ${ }^{6}$ Based on the excellent patency data, the 2018 European Society of Cardiology/European Association for Cardio-Thoracic Surgery Guidelines on myocardial revascularization recommend the no-touch SVG harvesting technique when an open technique is used. 
The predictive value of the recently proposed SAFINOUS score still needs to be validated in a large multicenter cohort to assess the performance of the tool, particularly in the extremes of the risk spectrum. As with any risk score, it is virtually impossible to take all potential risk factors into consideration. For clinical decision making and surgery planning of CABG patients, in addition to the SAFINOUS score, the potential benefit of no-touch SVG harvesting should be considered.

Tomislav Kopjar, $M D, P h D$

Hrvoje Gasparovic, $M D, P h D$

Bojan Biocina, $M D, P h D$

Department of Cardiac Surgery

University of Zagreb School of Medicine and University

Hospital Center Zagreb

Zagreb, Croatia

\section{References}

1. Antonopoulos AS, Odutayo A, Oikonomou EK, Trivella M, Petrou M, Collins GS, et al. Development of a risk score for early saphenous vein graft failure: an individual patient data meta-analysis. J Thorac Cardiovasc Surg. 2020;160:102-12.

2. Kodia K, Patel S, Weber MP, Luc JGY, Choi JH, Maynes EJ, et al. Graft patency after open versus endoscopic saphenous vein harvest in coronary artery bypass grafting surgery: a systematic review and meta-analysis. Ann Cardiothorac Surg. 2018;7:586-97.

3. Kopjar T, Dashwood MR. Endoscopic versus "no-touch" saphenous vein harvesting for coronary artery bypass grafting. Angiology. 2016;67:121-32.

4. Krishnamoorthy B, Critchley WR, Thompson AJ, Payne K, Morris J, Venkateswaran RV, et al. Study comparing vein integrity and clinical outcomes in open vein harvesting and 2 types of endoscopic vein harvesting for coronary artery bypass grafting. Circulation. 2017;136:1688-702.

5. Samano N, Geijer H, Liden M, Fremes S, Bodin L, Souza D. The no-touch saphenous vein for coronary artery bypass grafting maintains a patency, after 16 years, comparable to the left internal thoracic artery: a randomized trial. J Thorac Cardiovasc Surg. 2015;150:880-8.

6. Samano N, Souza D, Botelho Pinheiro B, Kopjar T, Dashwood M. Twenty-five years of no-touch saphenous vein harvesting for coronary artery bypass grafting: structural observations and impact on graft performance. Brazil J Cardiovasc Surg. 2020;35:91-100.

7. Sousa-Uva M, Neumann FJ, Ahlsson A, Alfonso F, Banning AP, Benedetto U, et al. 2018 ESC/EACTS guidelines on myocardial revascularization. Eur J Cardiothorac Surg. 2019;55:4-90.

\section{https://doi.org/10.1016/j.jtcvs.2020.03.155}

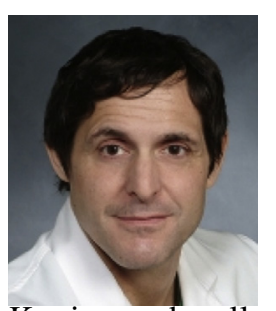

\section{REPLY: THE \\ NO-TOUCH \\ SAPHENOUS VEIN: \\ INCREASED PATENCY, \\ BUT AT WHAT RISK? \\ Reply to the Editor:}

I read with interest the letter by Kopjar and colleagues ${ }^{1}$ regarding the role of the notouch saphenous vein in coronary bypass surgery. There is no doubt that minimization of endothelial damage is key to the long-term patency rate of bypass conduit, and
The authors reported no conflicts of interest.

The Journal policy requires editors and reviewers to disclose conflicts of interest and to decline handling or reviewing manuscripts for which they may have a conflict of interest. The editors and reviewers of this article have no conflicts of interest.

in fact small randomized trials have reported excellent angiographic outcomes for the no-touch saphenous vein. $^{2}$ On the other hand, the no-touch harvesting technique is associated with a higher risk of surgical site complications, ${ }^{2}$ an issue particularly relevant for highrisk patients such as those with diabetes or obesity. Until we have clear data to understand the risk-to-benefit ratio between improved patency rate and increased risk of surgical complications with the no-touch saphenous vein, alternative conduits (the radial artery in particular) should be preferred.

Mario Gaudino, MD

Department of Cardiothoracic Surgery

Weill Cornell Medicine

New York City, NY

\section{References}

1. Kopjar T, Gasparovic H, Biocina B. The no-touch saphenous vein should be considered in a risk score of vein graft failure. J Thorac Cardiovasc Surg. 2020; 160:e1-2.

2. Deb S, Singh SK, de Souza D, Chu MWA, Whitlock R, Meyer SR, et al. SUPERIOR SVG: no touch saphenous harvesting to improve patency following coronary bypass grafting (a multi-centre randomized control trial, NCT01047449). J Cardiothorac Surg. 2019;14:85.

https://doi.org/10.1016/j.jtcvs.2020.03.154

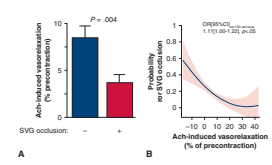

REPLY FROM

AUTHORS: VEIN

GRAFT BIOLOGY AND

THE RISK OF GRAFT

OCCLUSION

Reply to the Editor:

We thank Kopjar and colleagues ${ }^{1}$ for their letter on the Saphenous Vein Graft Failure-An Outcomes Study in Coronary Artery Bypass Grafting (SAFINOUS-CABG) study, ${ }^{2}$ and for giving us the opportunity to comment on the importance of vein harvesting for graft patency.

The SAFINOUS-CABG study ${ }^{2}$ was an international collaboration between cardiothoracic centers with shared individual patient data from patients undergoing CABG and available angiographic data within the first year after surgery, and as such it was the first systematic effort to develop a comprehensive prediction model for early 